\title{
A cross-sectional analytical study of geophagia practices and blood metal concentrations in pregnant women in Johannesburg, South Africa
}

\author{
A Mathee,,${ }^{1,2,3} \mathrm{PhD}$; N Naicker, ${ }^{1,2} \mathrm{MB}$ BCh, MMed, FCPHM, PhD; T Kootbodien, ${ }^{1} \mathrm{MB}$ ChB, MPH; \\ T Mahuma, ${ }^{1}$ MA (Anthropology); P Nkomo, ${ }^{1} \mathrm{MSc}$ (Med) (Epidemiology and Biostatistics); I Naik, ${ }^{4} \mathrm{MSc}$; \\ T de Wet ${ }^{5,6} \mathrm{PhD}$ \\ ${ }^{1}$ Environment and Health Research Unit, South African Medical Research Council, Johannesburg, South Africa \\ ${ }^{2}$ School of Public Health, Faculty of Health Sciences, University of the Witwatersrand, Johannesburg, South Africa \\ ${ }^{3}$ Faculty of Health Sciences, University of Johannesburg, South Africa \\ ${ }^{4}$ Analytical Services Department, National Institute for Occupational Health, Johannesburg, South Africa \\ ${ }^{5}$ Department of Anthropology and Development Studies, Faculty of Humanities, University of Johannesburg, South Africa \\ ${ }^{6}$ Centre for Anthropological Research, University of Johannesburg, South Africa
}

Corresponding author: T Kootbodien (tkootbodien@mrc.ac.za)

Background. Geophagia, a form of pica, has been shown to be widely practised in sub-Saharan Africa, especially among pregnant women. Objective. To assess the prevalence of geophagia and examine exposure to selected metals and associated risk factors in women attending an antenatal clinic at Rahima Moosa Mother and Child Hospital, Johannesburg, South Africa, during June and July 2010.

Methods. We conducted a cross-sectional study on a convenience sample of 307 pregnant women, ranging in age from 18 to 46 years. Structured interviews were conducted to understand geophagia practices. Blood samples were collected to determine haemoglobin values and concentrations of arsenic, cadmium, mercury and lead. Statistical analyses using the $\chi^{2}$ test, Wilcoxon's rank-sum test and logistic regression analyses were performed as appropriate.

Results. Mean parity was 1.4 and the mean (standard deviation) gestational age 30.3 (6.0) weeks. Geophagia was reported by 60 women (19.5\%), and the majority purchased soil from street vendors (83.3\%). The prevalence of anaemia in the study sample was $16.9 \%$ (95\% confidence interval 13.1 - 21.6\%). Geophagic women had significantly higher blood lead levels than non-geophagic women (2.1 v. $1.4 \mu \mathrm{g} / \mathrm{dl} ; \mathrm{p}<0.001)$. Anaemia, the use of African traditional medicines and craving of non-nutritive substances in a previous pregnancy were associated with geophagia.

Conclusions. Geophagia is practised by a considerable proportion of pregnant women in Johannesburg, especially migrant women. Greater vigilance in respect of pica, especially geophagia, may be needed as part of antenatal care programmes to avoid potentially detrimental health effects of the practice.

S Afr Med J 2014;104(8):568-573. DOI:10.7196/SAMJ.7466

Geophagia (intentional ingestion of soil/sand, clay blocks and mud) is defined as a form of pica, and has been known for centuries. ${ }^{[1]}$ A variety of reasons for geophagia have been postulated, including religious, cultural, nutritional and medicinal practices, famine, perceived enhancement of personal appearance, pregnancy-related cravings, and enjoyment of the taste, texture or smell of the substance consumed. ${ }^{[1-3]}$ Although the prevalence varies widely, geophagia 
continues to be practised in many parts of the world. It appears to be more common in children than in adults, in women than in men, in black people than in white people, in rural areas than in urban areas, and in pregnant women than in non-pregnant women. ${ }^{[4]}$ Pregnant women have been identified as a group in which geophagia is particularly widespread, and studies undertaken in Dar es Salaam (Tanzania) and Nairobi (Kenya) showed prevalences of $64 \%$ and $74 \%$, respectively. ${ }^{[5,6]}$

Few studies have described the practice of pica and geophagia in South Africa (SA). One of the first to be reported was an investigation of 12 children in Cape Town with pronounced geophagia and haemoglobin levels significantly lower than those in a control group. ${ }^{[7]}$ Geophagia was also reported in schoolchildren from KwaZulu-Natal Province, and was associated with elevated levels of helminthic infections. ${ }^{[8]}$ There is a paucity of studies of pica in pregnant SA women. ${ }^{[1]}$ One study reported that pica levels are highest in black African women from both rural and urban areas (44\% and 38\%, respectively). ${ }^{[9]}$ Among 240 Xhosa-speaking women aged $20-60$ years from the Eastern Cape Province, 75\% reported practising geophagia at some point in their lives. The frequency of soil ingestion varied from occasionally to several times a day, and three-quarters of the participants reported that their family members and friends were aware of their habit, and that they had encountered both approval and disapproval. ${ }^{[10]}$ Rural women obtained soil from a variety of locations, including local hills, mountains, gardens, riverbeds and termite mounds, while those in urban areas mainly purchased soil from street vendors. ${ }^{[10,11]}$ Most clays were heated before sale, for example by baking or boiling, which enhances the colour and may reduce the microbial load. ${ }^{[11]}$

While strongly held beliefs about the nutritional benefits and detoxifying effects of geophagia exist, ${ }^{[12]}$ ingestion of soil has been shown to interfere with the bioavailability of micronutrients (leading to micronutrient deficiencies), and may result in geohelminthic infections, anaemia, hypokalaemia, peritoneal mesothelioma and intestinal obstruction or perforation. ${ }^{[2,4,8]}$ Geophagic behaviour may also increase exposure to metal contaminants in the soil, including arsenic and lead - for example, elevated concentrations of arsenic were found in the baked clay (sikor) widely consumed by pregnant Bangladeshi women in the UK. ${ }^{[3]}$ A study in New York found women who practised pica to have higher blood lead levels than other women. ${ }^{[13]}$ Geophagia has also been associated with maternal dental injury, constipation, and dysfunctional labour due to intestinal obstruction. Possible fetal effects include low birth weight and lead exposure. ${ }^{[4]}$ SA case studies have reported hypokalaemia and iron deficiency anaemia among pregnant women practising geophagia. ${ }^{[1,15]}$ Despite being a well-established practice, geophagia during pregnancy remains an under-reported and understudied phenomenon, ${ }^{[1,4]}$ in part because it is often done covertly. This article describes the findings of a study of geophagia in an urban setting (Johannesburg, SA) and reflects on the implications for antenatal healthcare in SA and elsewhere.

\section{Methods}

We conducted a cross-sectional study, funded by the South African Medical Research Council, at the Rahima Moosa Mother and Child Hospital in Westbury, Johannesburg, during June and July 2010. Based on the prevalence of pica among pregnant women described by Walker et al. ${ }^{[9]}$ a sample of 288 pregnant women was required to obtain a $95 \%$ confidence interval (CI) and a power of $90 \%$, assuming a non-response rate of $20 \%$.

Pregnant women attending for routine antenatal care clinic visits, who were $\geq 18$ years of age and at $\geq 20$ completed weeks' gestation, were invited to participate. The study was explained to all prospective participants, and an information sheet was provided detailing the key elements of the study: completion of a questionnaire, donation of a blood sample for metal content analysis, and a haemoglobin test. A convenience sample of 333 pregnant women consented to participate in the face-to-face structured interview. In total 26 women were excluded, 15 because of incomplete questionnaires, ten who could not provide a blood sample and one who went into labour during the interview, leaving a final study sample of 307 . The overall study response rate was $92.1 \%$.

The interview questionnaire was administered in English by fieldworkers trained to obtain information on participants' socioeconomic status, obstetric history, past medical history and pica practices. Women who reported geophagic practices were asked to identify their sources of soil. Venous blood samples of approximately $7 \mathrm{ml}$ were drawn from the participants by professional nurses using aseptic techniques and collected into sterile ethylenediaminetetra-acetic acid (EDTA)-containing tubes. Blood samples were stored on ice and transported to the analytical laboratory on the day of fieldwork. Haemoglobin values were measured using a Hemocue $\mathrm{Hb} 201+$ haemoglobinometer. Women with anaemia were referred to an antenatal clinic for further investigation and treatment. Samples of maternal whole blood were also analysed for levels of arsenic, cadmium, mercury and lead. All analyses were performed using the inductively coupled plasma-mass spectrometry (ICP-MS) technique, with certified standards and reference materials used throughout.

\section{Statistical analysis}

Data were processed using Stata statistical software (version 11.0). Blood metal concentrations were not normally distributed and were presented using the geometric mean, 95\% CI, median and range. Anaemia was defined as a haemoglobin value $<10.5 \mathrm{~g} / \mathrm{dl}$. Nominal variables were described using the $\chi^{2}$ test or Fisher's exact test, as appropriate. Odds ratios (ORs) and $95 \%$ CIs were calculated using logistic regression to predict the sociodemographic characteristics and metal concentrations associated with geophagia. In multivariate regression analyses, variables with no significant effect measures were removed from the model in a stepwise manner and data were presented only for the best-fit model. A $p$-value of 0.05 was considered significant.

\section{Ethical approval}

Ethical approval for the study was obtained from the Human Research Ethics Committee of the University of the Witwatersrand, Johannesburg. Written consent forms were completed and signed prior to data collection and blood sampling. Participants were informed that participation was voluntary, and of their right to withdraw at any time without detrimental consequences.

Table 1. Prevalence of pica and geophagia in the study sample

\begin{tabular}{|c|c|c|}
\hline Substance ingested & $\begin{array}{l}\text { Pica prevalence in the total } \\
\text { sample }(N=307), \%\end{array}$ & Type of pica $(N=70), n(\%)$ \\
\hline Soil, clay and/or stones & 19.5 & $60(85.7)$ \\
\hline Chalk & 0.7 & $2(2.9)$ \\
\hline Toilet tissue & 0.7 & $2(2.9)$ \\
\hline Charcoal & 0.7 & $2(2.9)$ \\
\hline Other* & 1.3 & $4(5.7)$ \\
\hline Total & 22.8 & $70(100)$ \\
\hline
\end{tabular}




\section{Results}

\section{Profile of the study population}

The mean (standard deviation (SD)) age of the sample of women, $80.5 \%$ of whom had been born in SA, was 30 (6.1) years. Participants who had been born outside SA's borders (19.5\%) were from the following countries: Zimbabwe, Malawi, Nigeria, Zambia, Ethiopia,
Mali, Kenya, Somalia, Lesotho, Mozambique, Uganda, India, the Democratic Republic of the Congo, Ivory Coast, Rwanda and the Republic of Congo. A large proportion $(94.1 \%)$ of the women had achieved secondary or tertiary education, $40.4 \%$ were unemployed, and $16.9 \%$ reported a monthly household income of less than ZAR1 000 $( \pm$ US\$125). Over half $(53.8 \%)$ of the participants were from house-

\begin{tabular}{|c|c|c|c|c|c|}
\hline Risk factor & $\begin{array}{l}\text { Total sample } \\
(N=307), n(\%)\end{array}$ & $\begin{array}{l}\text { Subjects reporting geophagia } \\
\text { practices }(N=60), n(\%)\end{array}$ & Crude OR & 95\% CI & $p$-value \\
\hline \multicolumn{6}{|l|}{ Sociodemographic factors } \\
\hline \multicolumn{6}{|l|}{ Maternal age (years) } \\
\hline $18-30$ & $185(60.3)$ & $38(63.3)$ & 1 & & \\
\hline$>31$ & $122(39.7)$ & $22(36.7)$ & 0.7 & $0.38-1.21$ & 0.186 \\
\hline \multicolumn{6}{|l|}{ Nationality } \\
\hline SA & $247(80.5)$ & $41(68.3)$ & 1 & & \\
\hline Non-SA & $60(19.5)$ & $19(31.7)$ & 2.3 & $1.23-4.41$ & 0.010 \\
\hline \multicolumn{6}{|l|}{ Education } \\
\hline Secondary/tertiary & $289(94.1)$ & $53(88.3)$ & 1 & & \\
\hline None/primary & $18(5.9)$ & $7(11.7)$ & 2.8 & $1.04-7.65$ & 0.040 \\
\hline \multicolumn{6}{|l|}{ Household monthly income } \\
\hline$<\mathrm{R} 1000$ or no income at all & $52(16.9)$ & $11(18.3)$ & 1 & & \\
\hline R1 $000-5000$ & $165(53.8)$ & $42(70.0)$ & 1.3 & $0.60-2.70$ & 0.530 \\
\hline >R5 000 & $90(29.3)$ & $7(11.7)$ & 0.3 & $0.11-0.87$ & 0.026 \\
\hline \multicolumn{6}{|l|}{ Household size } \\
\hline$\geq 4$ & $133(53.8)$ & $23(38.3)$ & 1 & & \\
\hline$<3$ & $114(46.2)$ & $37(61.7)$ & 1.9 & $1.05-3.34$ & 0.033 \\
\hline \multicolumn{6}{|l|}{ Maternal smoking } \\
\hline No & $249(81.1)$ & $55(91.7)$ & 1 & & \\
\hline Yes & $58(18.9)$ & $5(8.3)$ & 0.3 & $0.12-0.87$ & 0.025 \\
\hline \multicolumn{6}{|l|}{ Maternal alcohol intake } \\
\hline No & $273(89.2)$ & $53(89.8)$ & 1 & & \\
\hline Yes & $33(10.8)$ & $6(10.2)$ & 0.9 & $0.36-2.35$ & 0.865 \\
\hline \multicolumn{6}{|l|}{ Traditional medicines* } \\
\hline No & $295(96.1)$ & $54(90.0)$ & 1 & & \\
\hline Yes & $12(3.9)$ & $6(10.0)$ & 4.7 & $1.39-14.37$ & 0.012 \\
\hline \multicolumn{6}{|l|}{ Pregnancy-related factors } \\
\hline \multicolumn{6}{|l|}{ Gestational age (weeks) } \\
\hline $20-32$ & $185(60.3)$ & $38(63.3)$ & 1 & & \\
\hline $33-36$ & $77(25.1)$ & $14(23.3)$ & 0.8 & $0.43-1.69$ & 0.663 \\
\hline$\geq 37$ & $45(14.6)$ & $8(13.4)$ & 0.8 & $0.35-1.94$ & 0.678 \\
\hline \multicolumn{6}{|l|}{$\begin{array}{l}\text { Reported craving in previous } \\
\text { pregnancy }\end{array}$} \\
\hline No & $180(58.6)$ & $19(31.7)$ & 1 & & \\
\hline Yes & $67(21.8)$ & $31(51.7)$ & 7.3 & $3.71-14.3$ & $<0.001$ \\
\hline Not pregnant previously & $60(19.6)$ & $10(16.6)$ & 1.7 & $0.73-3.88$ & 0.212 \\
\hline \multicolumn{6}{|l|}{ Haemoglobin $(\mathrm{g} / \mathrm{dl})$} \\
\hline$\geq 10.5$ & $255(83.1)$ & $42(70.0)$ & 1 & & \\
\hline$<10.5$ & $52(16.9)$ & $18(30.0)$ & 2.6 & $1.39-5.19$ & 0.003 \\
\hline
\end{tabular}


holds comprising four or more individuals. The mean gestational age was $30.3(6.0)$ weeks. The mean parity was 1.4 , and $22.6 \%$ of the women were nulliparous. Haemoglobin value determinations showed that $16.9 \%$ were anaemic $(95 \%$ CI $13.1-21.6 \%)$. Among those who had been pregnant previously, $21.8 \%$ reported having craved non-food substances during their previous pregnancy.

Of the study sample, $22.8 \%$ reported ingesting a variety of nonfood substances during the current pregnancy (Table 1). The majority of those with pica $(85.7 \%, 19.5 \%$ of the total sample) were ingesting soil, clay or stones (geophagia). Of those who reported geophagia, $83.3 \%$ purchased soil from street vendors. Twelve women $(3.9 \%$ of the total sample) also reported taking African traditional plant-based medicines (isihlambezo, imbiza or morroto wa-tshwene). Threequarters of those with pica had not informed health personnel of their practice. Reasons for non-disclosure included fear of censure, not having been asked about pica practices (had they been asked they would have disclosed), and a perception that pica was a normal, expected development during pregnancy and there was therefore no need to report it as unusual behaviour. Most of those who disclosed their pica behaviour to health personnel were advised to cease, while others were prescribed iron tablets, and one woman was counselled to decrease the amount of soil ingested.
Table 2 describes the univariate sociodemographic and pregnancyrelated factors associated with geophagia. Of the participants $10.8 \%$ and $18.9 \%$, respectively, reported using alcohol and tobacco during the current pregnancy. Tobacco use was more widespread in nongeophagic women $(21.5 \%$, compared with $8.3 \%$ in the geophagic group; $p=0.02$, Fisher's exact test), but levels of alcohol consumption were similar in the two groups. Consumption of African traditional medicines such as isihlambezo was more widespread in geophagic women (10.0\% compared with $2.4 \%$ in non-geophagic women; $p=0.007, \chi^{2}$ test). Of the women who practised geophagia, $51.7 \%$ $(31 / 60)$ reported having craved non-food substances in a previous pregnancy, compared with $14.6 \%(36 / 247)$ in the non-geophagia group ( $p=0.001, \chi^{2}$ test). There were no differences across the two groups with regard to pregnancy-related symptoms such as morning sickness, heartburn, constipation and moodiness, bleeding during pregnancy, or reported levels of urinary tract infections. Geophagic women had significantly lower mean haemoglobin levels than nongeophagic women $(11.2 \mathrm{~g} / \mathrm{dl}$ v. $12.0 \mathrm{~g} / \mathrm{dl} ; p=0.002$, Wilcoxon ranksum test).

Women who practised geophagia were more likely to have been born outside SA (crude OR 2.3; 95\% CI 1.23 - 4.41) and to have lower educational status (never been to school or had only primary school

Table 3. Distribution of blood metal concentrations in the total sample $(N=307)$

\begin{tabular}{|c|c|c|c|c|}
\hline Metal & Geometric mean & 95\% CI & Median (range) & Reference level $(\mu \mathrm{g} / \mathrm{dl})(\%>$ reference level $)$ \\
\hline Lead & 0.83 & $0.90-1.04$ & $1.4(1.0-9.9)$ & $5^{\star}(2.3)$ \\
\hline Mercury & 0.76 & $0.71-0.81$ & $0.6(0.5-21.2)$ & $5^{\dagger}(1.6)$ \\
\hline \multirow[t]{2}{*}{ Cadmium } & 0.24 & $0.21-0.26$ & $0.2(0.1-14.3)$ & Smokers: $3.36^{\ddagger}(1.8)$ \\
\hline & & & & Non-smokers: $1.12(2.4)$ \\
\hline Arsenic & 0.84 & $0.79-0.89$ & $0.8(0.2-5.9)$ & $10^{\ddagger}(0)$ \\
\hline \multicolumn{5}{|c|}{ 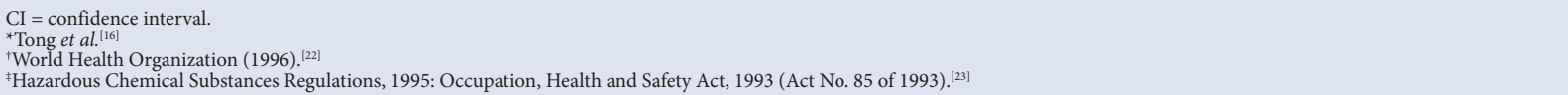 } \\
\hline
\end{tabular}

Table 4. Blood metal concentrations according to geophagia status

\begin{tabular}{|c|c|c|c|c|c|}
\hline & $n$ & Geometric mean & $95 \% \mathrm{CI}$ & Median (range) & $p$-value* \\
\hline \multicolumn{6}{|l|}{ Lead $(\mu \mathrm{g} / \mathrm{dl})$} \\
\hline No geophagia & 247 & 1.44 & $1.37-1.52$ & $1.30(1.00-9.90)$ & \\
\hline Geophagia & 60 & 2.06 & $1.79-2.37$ & $2.00(1.00-8.60)$ & $<0.001^{\dagger}$ \\
\hline \multicolumn{6}{|l|}{ Mercury ( $\mu \mathrm{g} / \mathrm{l})$} \\
\hline No geophagia & 247 & 0.77 & $0.71-0.83$ & $0.64(0.50-21.24)$ & \\
\hline Geophagia & 60 & 0.72 & $0.62-0.83$ & $0.57(0.50-11.15)$ & 0.183 \\
\hline \multicolumn{6}{|l|}{ Arsenic ( $\mu \mathrm{g} / \mathrm{dl})$} \\
\hline No geophagia & 247 & 0.83 & $0.78-0.89$ & $0.83(0.24-5.89)$ & \\
\hline Geophagia & 60 & 0.86 & $0.75-0.98$ & $0.82(0.29-3.94)$ & 0.664 \\
\hline \multicolumn{6}{|l|}{ Cadmium ( $\mu \mathrm{g} / \mathrm{l})$} \\
\hline \multicolumn{6}{|l|}{ Smoking } \\
\hline No geophagia & 53 & 0.52 & $0.40-0.67$ & $0.59(0.10-4.70)$ & \\
\hline Geophagia & 5 & 0.31 & $0.11-0.85$ & $0.18(0.15-0.80)$ & 0.319 \\
\hline \multicolumn{6}{|l|}{ Non-smoking } \\
\hline No geophagia & 194 & 0.20 & $0.18-0.22$ & $0.17(0.10-14.25)$ & \\
\hline Geophagia & 55 & 0.20 & $0.17-0.24$ & $0.18(0.10-4.23)$ & 0.901 \\
\hline
\end{tabular}


education) (crude OR 2.8; 95\% CI 1.04 7.65). Geophagic women also tended to be part of a smaller household (crude OR 1.9; $95 \%$ CI 1.05 - 3.34). Only $3.8 \%$ of women used traditional African medicines; however, those who did so had a higher likelihood of being geophagic (crude OR 4.7; 95\% CI 1.39 14.37). In addition, women who reported having craved non-food substances in a previous pregnancy (crude OR 7.3; 95\% CI $3.71-14.31$ ) and those with anaemia (crude OR 2.6; 95\% CI 1.39 - 5.19) were more likely to practise geophagia.

\section{Blood metal analyses}

Table 3 shows the distribution of levels of lead, mercury, cadmium and arsenic in the blood samples collected, while Table 4 summarises the blood metal distributions in relation to geophagia status. The majority of women had blood metal distributions that were below international reference levels. For example, only $2.3 \%$ of the study sample had a blood lead level that exceeded the current reference level of $5 \mu \mathrm{g} /$ $\mathrm{dl}$ of the Centers for Disease Control and Prevention in the USA. ${ }^{[17]}$ The geometric mean blood lead level in geophagic women was $2.1 \mu \mathrm{g} / \mathrm{dl}$, as opposed to $1.4 \mu \mathrm{g} / \mathrm{dl}$ in non-geophagic women $(p<0.001$, Wilcoxon rank-sum test). Univariate analysis of the association between geophagia and blood lead levels showed a weak but significant association (crude OR 5.81; 95\% CI 1.26 $26.69 ; p=0.024$ ). Levels of mercury, arsenic and cadmium were not similarly elevated in women with geophagia. However, among women with geophagia, those from outside SA had a small but significantly elevated geometric mean blood mercury concentration $(0.97 \mu \mathrm{g} / \mathrm{l})$ compared with SA women $(0.62 \mu \mathrm{g} / \mathrm{l} ; p<0.001$, Wilcoxon rank-sum test).

Table 5 shows the results of multivariate modelling to examine the relationships between factors related to geophagia practices and metal concentrations. In the final model, geophagia was not associated with maternal age, alcohol intake, gestational age or elevated blood mental concentrations. After adjusting for education levels and household size, geophagia practices in this study sample were strongly associated with being born outside SA (OR 2.74; 95\% CI 1.27 - 5.92; $p=0.010$ ), and there was a weak but significant association with ingestion of traditional medicines (OR $6.74 ; 95 \%$ CI $1.75-26.04 ; p=0.006$ ). Geophagia in the current pregnancy was also associated with having craved non-food substances in a previous pregnancy (OR 8.00; 95\% CI 3.82 16.77; $p<0.001$ ), and women who practised geophagia had an increased likelihood of

Table 5. Multivariate associations of factors with geophagia among pregnant women

\begin{tabular}{|c|c|c|c|}
\hline Risk factor & Adjusted OR & $95 \% \mathrm{CI}$ & $p$-value \\
\hline \multicolumn{4}{|l|}{ Nationality } \\
\hline SA & 1 & & \\
\hline Non-SA & 2.7 & $1.27-5.92$ & 0.010 \\
\hline \multicolumn{4}{|l|}{ Education } \\
\hline Secondary/tertiary & 1 & & \\
\hline None/primary & 2.6 & $0.79-8.7$ & 0.116 \\
\hline \multicolumn{4}{|l|}{ Household size } \\
\hline$\geq 4$ & 1 & & \\
\hline$<3$ & 1.7 & $0.77-2.87$ & 0.235 \\
\hline \multicolumn{4}{|l|}{ Traditional medicines } \\
\hline No & 1 & & \\
\hline Yes & 6.7 & $1.75-26.04$ & 0.006 \\
\hline \multicolumn{4}{|l|}{$\begin{array}{l}\text { Reported craving in previous } \\
\text { pregnancy }\end{array}$} \\
\hline No & 1 & & \\
\hline Yes & 8.0 & $3.82-16.77$ & $<0.001$ \\
\hline Not pregnant previously & 1.5 & $0.64-3.72$ & 0.333 \\
\hline \multicolumn{4}{|l|}{ Anaemia } \\
\hline $\mathrm{Hb} \geq 10.5 \mathrm{~g} / \mathrm{dl}$ & 1 & & \\
\hline $\mathrm{Hb}<10.5 \mathrm{~g} / \mathrm{dl}$ & 2.6 & $1.19-5.46$ & 0.015 \\
\hline
\end{tabular}

being anaemic (OR 2.55; 95\% CI 1.19 - 5.46; $p=0.015$ ).

\section{Discussion}

The prevalence of geophagia in the current study is not as widespread as observed in earlier studies in other African countries (where levels around $64-74 \%$ have been reported) $)^{[5,6]}$ or elsewhere in SA. ${ }^{[10]}$ This may indicate a declining trend, or low levels of practice of geophagia in the our setting. Nevertheless it remains an important public health concern that one-fifth of the women recruited into this study intentionally ingested soil, and were at elevated risk of the concomitant detrimental maternal and fetal health effects. Furthermore, underreporting is a possibility, since there is evidence from this study that geophagia was practised in a clandestine fashion. While some women readily reported their pica behaviour to health personnel (and were usually advised to desist or decrease the habit, or were prescribed iron supplements), others deliberately concealed the practice, fearing censure. Others believed pica to be a normal and expected development in pregnancy and did not consider there to be any need to report or seek advice in respect of the habit.
Despite no significant association between geophagia and blood lead concentrations being observed in the multivariate model, it is suggested that caution and further investigation is warranted, especially in the light of such associations being observed elsewhere. ${ }^{[13]}$ Given the known toxicity ${ }^{[16]}$ and transplacental movement properties ${ }^{[17]}$ of lead, there is a particular need for vigilance in African settings where lead exposure is a public health concern. ${ }^{[17]}$ Geophagia was not associated with elevated blood levels of cadmium, arsenic or mercury in this study. However, women born outside SA were shown to have higher blood mercury levels than their local counterparts; we can suggest no explanation for this finding at this stage.

The association between geophagia and depressed haemoglobin levels was confirmed in this study. Geophagia has been shown to exacerbate the existing physiological risk of anaemia during pregnancy. ${ }^{[18]} \mathrm{A}$ further potential concern is the finding that women who were geophagic also tended to consume isihlambezo, a collective term used to describe a wide range of African traditional medicine formulations usually used during the last trimester of pregnancy to promote health and facilitate childbirth. ${ }^{[19]}$ The use of certain isihlambezo ingredients has been 
associated with detrimental pregnancy outcomes such as death due to hepatorenal failure, low birth weight, meconium staining of amniotic fluid and fetal distress. ${ }^{[19]}$

Screening for pica or geophagia does not currently constitute part of the standard antenatal assessment programme in SA. In this study one-fifth of women reported geophagia, and studies undertaken elsewhere provide evidence that levels may be even higher in other settings ${ }^{[5,6,10]}$ Given the high prevalence of geophagia, its association with depressed haemoglobin levels, and the potential for elevated blood lead levels and simultaneous use of isihlambezo (with its own potential concomitant health risks), it may be prudent to include active screening for pica or geophagia in the prenatal care programme in SA. Such a step may prove to be a powerful mechanism for antenatal education and identification of a range of maternal and fetal health risks, such as elevated blood lead levels, anaemia, geohelminthic infections, micronutrient deficiencies, intestinal obstruction or perforation, low birth weight and fetal distress. Since this study shows geophagia to be particularly prevalent in pregnant women from countries elsewhere in Africa, similar measures may be of benefit across a large cross-section of the African continent, as well as in African diaspora communities across the globe. ${ }^{[13,20,21]}$

\section{Conclusion}

Twenty per cent of pregnant women in this study undertaken in Johannesburg, SA, were geophagic, and at risk of anaemia and potentially lead exposure and other adverse health outcomes. Geophagia does not currently form part of the standard prenatal screening package in SA, but its inclusion potentially constitutes a powerful mechanism for antenatal education and the identification of a range of detrimental health outcomes.

\section{References}

1. Woywodt A, Kiss A. Geophagia: The history of earth-eating. J R Soc Med 2002;95(3):143-146. [http:// dx.doi.org/10.1258/irsm.95.3.143]

2. Niru $\mathrm{H}$, Elchalal U, Paltiel O Geophagy during pregnancy in Africa: A literature review. Obstet 2. Njiru H, Elchalal U, Paltiel O. Geophagy during pregnancy in Africa: A literature re
Gynecol Surv 2011;66(7):452-459. [http://dx.doi.org/10.1097/OGX.0b013e318232a034]
3. Al-Rmalli SW, Jenkins RO, Watts MJ, et al. Risk of human exposure to arsenic and other toxic elements from geophagy: Trace element analysis of baked clay using inductively coupled plasma mass elements from geophagy: Trace element analysis of baked clay using inductively coupled

spectrometry. Environ Health 2010;9(1):79. [http://dx.doi.org/10.1186/1476-069X-9-79]
4. Simpson E, Mull JD, Longley E, et al. Pica during pregnancy in low-income women born in Mexico. West J Med 2000;173(1):20-24. [http://dx.doi.org/10.1136/ewjm.173.1.20]

West J Med 2000;173(1):20-24. [http://dx.doi.org/10.1136/ewjm.173.1.20]
5. Nyaruhucha CN. Food cravings, aversions and pica among pregnant women in Dar es Salaam, 5. Nyaruhucha CN. Food cravings, aversions and
Tanzania. Tanzan J Health Res 2009;11(1):29-34.

6. Ngozi PO. Pica practices of pregnant women in Nairobi, Kenya. East Afr Med J 2008;85(2):72-79. [http://dx.doi.org/10.4314/eamj.v85i2.9609]

7. Lanzkowsky P. Investigation into the aetiology and treatment of pica. Arch Dis Child 1959;34(174):140148. [http://dx.doi.org/10.1136/adc.34.174.140]

8. Saathoff E, Olsen A, Kvalsvig JD, et al. Geophagy and its association with geohelminth infection in rural schoolchildren from northern KwaZulu-Natal, South Africa. Trans R Soc Trop Med Hy 2002;96(5):485-490. [http://dx.doi.org/10.1016/S0035-9203(02)90413-X]

9. Walker AR, Walker BF, Jones J, et al. Nausea and vomiting and dietary cravings and aversions during pregnancy in South African women. Br J Obstet Gynaecol 1985;92(5):484-489. [http://dx.do org/10.1111/j.1471-0528.1985.tb01353.x]

10. George G, Ndip E. Prevalence of geophagia and its possible implications to health - a study in rural South Africa. Presented at the 2nd International Conference on Environmental Science and Development (IPCBEE), Singapore, 26-28 February 2011. http://www.ipcbee.com/vol4/37 ICESD2011D10046.pdf (accessed 2 July 2014).

11. Ekosse GIE, de Jager L, Ngole V. Traditional mining and mineralogy of geophagic clays from Limpopo and Free State provinces, South Africa. African Journal of Biotechnology 2010;9(47):8058-8067. [http://dx.doi.org/10.5897/AJB10.296]

2. Johns T, Duquette M. Detoxification and mineral supplementation as functions of geophagy. Am J Clin Nutr 1991;53(2):448-456.

13. Thihalolipavan S, Candalla BM, Ehrlich J. Examining pica in NYC pregnant women with elevated bloo lead levels. Matern Child Health J 2013;17(1):49-55. [http://dx.doi.org/10.1007/s10995-012-0947-5]

14. McKenna D. Myopathy, hypokalaemia and pica (geophagia) in pregnancy. Ulster Med J 2006;75(2):159-160 5. Chaushev P, Dreyer M, Gledhill R. Hypokalemic myopathy due to ingestion of earth. J Neuro 2003;250(1):114-115. [http://dx.doi.org/10.1007/s00415-003-0934-2]

16. Tong S, von Schirnding YE, Prapamontol T. Environmental lead exposure: A public health problem of global dimensions. Bull World Health Organ 2000;78(9):1068-1077.

17. Goyer RA. Transplacental transport of lead. Environ Health Perspect 1990;89(6):101-105. [http:// dx.doi.org/10.1289/ehp.9089101]

18. Kwong WT, Phyllis F, Semba RD. Interactions between iron defeciency and lead poisoning Epidemiology and pathogenesis. Sci Total Environ 2004;330(1):21-37. [http://dx.doi.org/10.1016/] scitotenv.2004.03.017

19. Veale DJ, Furman KI, Oliver DW. South African traditional herbal medicines used during pregnancy and childbirth. J Ethnopharmacol 1992;36(3):185-191. [http://dx.doi.org/10.1016/0378-8741(92)90043-Q]

20. Klitzman S, Sharma A, Nicaj L, et al. Lead poisoning among pregnant women in New York City: Risk factors and screening practices. J Urban Health 2002;79(2):225-237. [http://dx.doi.org/10.1093/ jurban/79.2.225]

21. Abrahams PW, Follansbee MH, Hunt A, et al. Iron nutrition and possible lead toxicity: An appraisal of geophagy undertaken by pregnant women of UK Asian communities. Appl Geochem 2006;21(1):98108. [http://dx.doi.org/10.1016/j.apgeochem.2005.09.015]

22. World Health Organization. Trace elements in human nutrition and health. 1996. http://www.who.int nutrition/publications/micronutrients/9241561734/en/ (accessed 2 July 2014).

23. Hazardous Chemical Substances Regulations, 1995: Occupation, Health and Safety Act, 1993 (Act No. 85 of 1993). http://wwwlabour.gov.za/DOL/downloads/legislation/acts/occupational-health-and-safety/ amendments/Amended\%20Act\%20-\%20Occupational\%20Health\%20and\%20Safety.pdf (accessed 2 July 2014).

Accepted 15 May 2014 